\title{
Níveis de ácido fólico sérico em lactentes eutróficos, alimentados com leite materno, leite de vaca ou fórmula modificada
}

Serum folic status in eutrophic infants nourished with breast milk, cow milk or milk modified formula

Izilda das Eiras Tâmega1 ${ }^{1}$ Clóvis Duarte Costa²

\section{RESUMO}

Objetivo: Verificar os níveis de ácido fólico em três grupos de lactentes e comparar os valores encontrados; avaliar a necessidade de suplementação dessa vitamina aos quatro meses, quando as reservas teciduais são escassas e as fontes dietéticas pobres em folatos, em um período no qual a alimentação é exclusivamente láctea.

Métodos: Foram analisados os níveis de ácido fólico sérico, obtidos pelo método de radioimunoensaio, em 120 lactentes eutróficos, aos quatro meses, com alimentação láctea exclusiva, sendo $40 \mathrm{com}$ aleitamento materno, $40 \mathrm{com}$ leite de vaca pasteurizado e fervido e 40 com fórmula láctea industrializada e enriquecida com ácido fólico.

Resultados: Os níveis de ácido fólico sérico nos lactentes alimentados exclusivamente com leite de vaca pasteurizado e fervido foram significativamente menores do que os dos lactentes alimentados com leite materno e os alimentados com fórmula láctea modificada, enriquecida com folatos. Estes dois últimos grupos não mostraram diferenças entre si.

Conclusões: $\mathrm{O}$ estudo ressalta a necessidade de suplementação de ácido fólico nos lactentes aos quatro meses alimentados exclusivamente com leite de vaca. A pasteurização e a fervura do leite de vaca, habitualmente utilizadas, levam à deficiência dessa vitamina, tão importante na nutrição humana.

Palavras-chave: Ácido fólico; lactente; leite humano.

\section{ABSTRACT}

Objective: To study and to compare the status of serum folic acid in three groups of infants and to evaluate the need of supplying this vitamin in 4-month old infants, when tissue reserves are low and dietetic resources (exclusive milk feeding) are poor in folates.

Methods: Serum folic acid levels were analyzed by radioimmunoassay method in 120 eutrophic infants with four months of age. These infants were exclusively milk fed. Among them, 40 were nourished with human milk, 40 with boiled pasteurized cow milk and 40 with industrialized milk formula enriched with folic acid.

Results: Folic acid levels in infants exclusively nourished with boiled and pasteurized cow milk were significantly lower than those found in infants fed with either breast milk or formula enriched with folates. These last two groups did not show differences between them.

Conclusions:The study shows the need of the folic acid supplementation in 4-month old infants exclusively nourished with boiled pasteurized, since its use can led to deficiency of this vitamin so important in human nutrition.

Key-words: Folic acid; infant; milk, human.

\footnotetext{
Pediatra nutróloga e professora assistente mestre da Disciplina de Pediatria da Faculdade de Medicina de Sorocaba da Pontifícia Universidade Católica de São Paulo (PUC/SP)

${ }^{2}$ Pediatra gastroenterologista e professor titular da Disciplina de Pediatria da Faculdade de Medicina de Sorocaba da PUC/SP
}

Endereço para correspondência:

Izilda das Eiras Tâmega
Avenida Moreira César, 242, apto. 173

CEP 18010-010 - Sorocaba/SP

E-mail: izildatamega@gmail.com

Fonte financiadora: Laboratório de Investigações Diagnósticas

Recebido em: 2/1/2007

Aceito em: 12/2/2007 


\section{Introdução}

A descoberta das vitaminas representou importante avanço no estudo da nutrição humana, possibilitando a prevenção e o tratamento adequado de inúmeras doenças ${ }^{(1)}$. Embora indispensáveis à vida, as doses de vitaminas necessárias ao organismo são muito pequenas e, geralmente, supridas por dieta completa e equilibrada ${ }^{(2,3)}$. Em algumas situações clínicas, como prematuridade, infecções adquiridas e puericultura inadequada, entre outras, pode haver déficit de vitaminas ${ }^{(4-7)}$.

Dentre as vitaminas do complexo B, o ácido fólico (vitamina B11) é considerado como nutriente essencial ao ser humano. Descoberto em 1930, foi isolado em 1941 a partir das folhas do espinafre; daí o nome fólico: do latim folha ${ }^{(8,9)}$.

A vitamina B12 é um co-fator essencial para o metabolismo do ácido fólico e para a síntese de DNA e RNA ${ }^{(7)}$. A carência de ácido fólico manifesta-se inicialmente nos tecidos de crescimento mais rápido, como a medula óssea (eritropoiese) a e mucosa do trato gastrointestinal ${ }^{(6,7,10,11)}$.

Em relação às fontes do ácido fólico, apesar de a vitamina estar presente na maioria dos alimentos, quantidades apreciáveis são encontradas no fígado, rins, vegetais de folhas verdes-escura, aspargos, feijões e cereais integrais. É importante ressaltar a laranja, inclusive o seu suco congelado e reconstituído, como fonte de ácido fólico sob forma de monoglutamato, o qual não requer hidrólise para a absorção ${ }^{(12-15)}$.

O ácido fólico é muito vulnerável ao armazenamento de vegetais, cocção demorada ou outro tipo de processamento como: enlatamento, refinação, pasteurização e exposição à luz e ao sol. Há perda de 50 a 95\% durante a cocção. O leite de vaca (LV) in natura, quando fervido, apresenta perda de $44 \%$ de ácido fólico e, se previamente pasteurizado (que, em geral, é o de uso mais rotineiro), há perda de aproximadamente $74 \%{ }^{(16-}$ 18). O leite materno (LM), apesar de pobre em ácido fólico, parece suprir as necessidades do lactente jovem, em virtude da melhor biodisponibilidade, quando comparado ao LV.

Considerando-se a fonte láctea, o LM contém cerca de $5 \mathrm{mcg} / 100 \mathrm{~mL}$ de ácido fólico, o LV in natura contém em média $5,9 \mathrm{mcg} / 100 \mathrm{~mL}$, o LV modificado é acrescido de aproximadamente $6,1 \mathrm{mcg} / 100 \mathrm{~mL}$ e o leite de cabra in natura apresenta apenas traços de folato, cerca de $1,0 \mathrm{mcg} / 100 \mathrm{~mL}^{(12,19,20)}$.

O requerimento diário de folato é progressivo durante a infância: no primeiro ano, $65-80 \mathrm{mcg} ; 1-12$ anos, 150-200mcg; acima de 12 anos e adultos 300-400mcg. Está necessidade altera-se em situações nas quais ocorrem modificações do metabolismo: gestação $=600 \mathrm{mcg}$ e lactação $=500 \mathrm{mcg}^{(20-22)}$. Atualmente, o ácido fólico é comer- cializado sob forma de preparações isoladas ou associadas a outras vitaminas e sais minerais.

Estudos mostraram que lactentes alimentados com LM, de mães suplementadas ou não com ácido fólico, mantêm níveis similares de folato sanguíneo, observando-se valores altos do primeiro ao terceiro mês de vida, com queda gradual e posterior estabilização até o nono mês, independentemente do nível fólico materno ${ }^{(23,24)}$.

Olivares et al ${ }^{(25)}$ verificaram que, em recém-nascidos alimentados com leite artificial não acrescido de folatos, a dosagem de ácido fólico sangüínea é alta na primeira semana de vida, diminuindo rapidamente, e, na oitava semana, atinge valor muito baixo, que oscila durante todo o primeiro ano de vida. Por outro lado, Smith et a ${ }^{(26)}$ e Salmenpera et a $l^{(27)}$ mostraram que, com a introdução de alimentos complementares e utilizando-se leite artificial enriquecido com folatos, os níveis sangüíneos de ácido fólico foram equivalentes aos encontrados em lactentes em aleitamento materno exclusivo.

A seqüência de eventos hematológicos, na depleção de ácido fólico, inicia-se com baixo teor de folato sérico logo após duas semanas, folato eritrocitário após 16 semanas e anemia após 20 semanas $^{(28)}$. Do ponto de vista laboratorial, dados de literatura mostram que a dosagem de folato sérico, quando comparada à de folato eritrocitário e à de outros valores indiretos (hipersegmentação dos neutrófilos e volume corpuscular médio), mostra-se superior para avaliar o suprimento alimentar de ácido fólico ${ }^{(25,29,30)}$.

Em face ao exposto, o presente trabalho tem como objetivo verificar os níveis de ácido fólico sérico em três grupos distintos de lactentes eutróficos aos quatro meses, sendo um deles sob aleitamento materno exclusivo; outro alimentado exclusivamente com leite de vaca pasteurizado e fervido; e outro alimentado exclusivamente com fórmula láctea industrializada enriquecida com ácido fólico. Além disso, este trabalho visa comparar os valores de ácido fólico sérico nos três grupos acima referidos e, finalmente, observar a necessidade de suplementação de ácido fólico nos lactentes alimentados com as três formas de alimentação láctea.

\section{Métodos}

O presente estudo foi aprovado pelo Comitê de Ética em Pesquisa da Faculdade de Medicina de Sorocaba da Pontifícia Universidade Católica de São Paulo (PUC/SP). Um termo de consentimento livre e esclarecido foi assinado previamente pelos pais ou responsáveis para a inclusão do lactente no trabalho. 
Os lactentes foram selecionados a partir do primeiro mês de vida no ambulatório de Puericultura da Disciplina de Pediatria, localizado no Conjunto Hospitalar de Sorocaba, no período de outubro de 1995 a setembro de 1997. Na ocasião, as mães foram orientadas a manter como alimento único até o quarto mês o mesmo tipo de leite que estava sendo ofertado. Se o lactente estivesse em aleitamento materno, este sempre era estimulado. A conduta nutricional adotada seguiu as normas dos Departamentos de Nutrição das Sociedades Brasileira e Paulista de Pediatria ${ }^{(5,9)}$, que orientam a suplementação vitamínica nos lactentes a partir de um mês, principalmente naqueles com leite de vaca não modificado. Dos 125 lactentes inicialmente escolhidos, foram selecionados 103 , pois em 16 houve oferta de diferentes tipos de leite de maneira alternada e, em seis lactentes, as mães introduziram por conta própria frutas e/ou cereais aos três meses. Outra dificuldade encontrada foi a obtenção de lactentes alimentados artificialmente com leites modificados ou não, visto que, em nosso serviço o incentivo ao aleitamento materno é prioritário. Por outro lado, houve boa aceitação por parte dos pais, quando eram informados de que se tratava de um trabalho que envolvia aspectos nutricionais, pois, geralmente, há grande interesse na adequação alimentar dos filhos.

Os 103 lactentes escolhidos eram de ambos os gêneros, eutróficos, nascidos a termo, adequados para a idade gestacional, sem intercorrências infecciosas, hematológicas ou neurológicas. Foram excluídos os que estivessem fazendo uso de vitaminas à base de ácido fólico e sais de ferro.

Os lactentes foram divididos em três grupos: Grupo I, com 40 lactentes em aleitamento materno exclusivo, sendo 20 do gênero masculino; Grupo II, com 35 lactentes alimentados exclusivamente com leite de vaca pasteurizado e fervido, sendo 14 do gênero masculino; e Grupo III, com 28 lactentes alimentados exclusivamente com leite de vaca modificado e enriquecido com vitaminas, incluindo ácido fólico, sendo 15 do gênero masculino.

Aos quatro meses, os lactentes foram submetidos à coleta de $6 \mathrm{~mL}$ de sangue, dos quais $2 \mathrm{~mL}$ foram centrifugados. $\mathrm{O}$ soro separado era mantido congelado e livre da exposição solar. Procedeu-se à dosagem de ácido fólico sérico e de vitamina
B12 sérica por meio do método de Dualcount fase sólida, por radioimunoensaio, sendo feita a leitura pelo contador gama ICN/Isomedic ${ }^{\circledR}$. O método de Dualcount é de alta precisão, sensibilidade e especificidade, detectando na mesma amostra os níveis de ácido fólico e vitamina $\mathrm{B} 12^{(30,31)}$. Os valores de referência para o ácido fólico são 3-17ng/mL e para a vitamina B12, 200-950pg $/ \mathrm{mL}$. Outras dosagens laboratoriais analisadas e seus valores de referência foram: ferro sérico $(50-150 \mathrm{mcg} / \mathrm{dL}$ ), hemoglobina (9,5-11,5g/dL), volume corpuscular médio (74$\left.91 \mu^{3}\right)$ e reticulócitos $\left(35-10510^{3} / \mathrm{mm}^{3}\right)^{(6,25,26)}$.

$\mathrm{Na}$ análise estatística dos resultados, foram utilizados testes não paramétricos, levando-se em consideração a natureza das distribuições de valores das variáveis estudadas ou a variabilidade das medidas efetuadas ${ }^{(32,33)}$. Aplicou-se o teste de Mann-Whitney para duas amostras independentes com o objetivo de comparar os gêneros em relação aos valores das variáveis estudadas. Em alguns casos estudados, levando-se em conta o tamanho da amostra, esse teste foi aplicado com aproximação à curva normal ( $\mathrm{z}$ calculado). Usou-se também a análise de variância por postos de Kruskal-Wallis com a finalidade de comparar os três grupos a serem estudados quanto aos valores das variáveis consideradas. Diante de diferenças significantes, essa análise foi complementada pelo teste de comparações múltiplas. Finalmente, empregou-se o coeficiente de correlação de Spearman para estudar as relações entre valores do ácido fólico e os valores das demais variáveis consideradas. Em todos os testes fixou-se em $5 \%(p<0,05)$ o nível para rejeição da hipótese de nulidade.

\section{Resultados}

As dosagens do ácido fólico abaixo do valor referencial foram encontradas em cinco lactentes do Grupo I (LM), oito do Grupo II (LV) e quatro do Grupo III (fórmula), não havendo diferença significante entre os gêneros nos três grupos. As médias dos valores séricos do ácido fólico foram: Grupo $\mathrm{I}=8,34 \mathrm{ng} / \mathrm{mL}$; Grupo II = 5,07ng/mL e Grupo III=8,22ng/ $\mathrm{mL}$, mostrando diferença estatística significante por meio da análise de variância e testes de comparações múltiplas (H calculado: 9,73 e H crítico: 5,99), conforme Tabela 1.

Tabela 1 - Média dos valores dos níveis de ácido fólico, vitamina B12, ferro sérico, hemoglobina, VCM e reticulócitos nos Grupos I (leite materno), II (leite de vaca) e III (fórmula)

\begin{tabular}{lcccccc}
\hline $\begin{array}{l}\text { Grupos/ } \\
\text { exames }\end{array}$ & $\begin{array}{c}\text { Ácido fólico } \\
(\mathbf{n g} / \mathbf{m L})\end{array}$ & $\begin{array}{c}\text { Vitamina B12 } \\
(\mathbf{p g} / \mathbf{m L})\end{array}$ & $\begin{array}{c}\text { Ferro } \\
(\mathbf{m c g} / \mathbf{d L})\end{array}$ & $\begin{array}{c}\text { Hemoglobina } \\
(\mathbf{g} / \mathbf{d L})\end{array}$ & $\begin{array}{c}\text { VCM } \\
\left(\boldsymbol{\mu}^{3}\right)\end{array}$ & $\begin{array}{c}\text { Reticulócitos } \\
\left(\mathbf{1 0}^{3} / \mathbf{m m}^{3}\right)\end{array}$ \\
\hline G I & 8,34 & 589,9 & 64,8 & 9,41 & 82,4 & 70,3 \\
G II & 5,07 & 489,6 & 58,9 & 9,29 & 81,8 & 75,0 \\
G III & 8,22 & 573,8 & 63,1 & 9,38 & 82,3 & 76,2 \\
\hline
\end{tabular}


As dosagens de vitamina B12 estiveram abaixo do valor referencial em um lactente do Grupo I, três do Grupo II e nenhum do Grupo III. As médias obtidas foram para o Grupo I: $589,9 \mathrm{pg} / \mathrm{mL}$; para o Grupo II. 489,6pg/mL e para o Grupo III: $573,8 \mathrm{pg} / \mathrm{mL}$, não havendo diferença estatística significante (H calculado: 5,30 e H crítico: 5,99).

As dosagens de ferro sérico estiveram abaixo do valor referencial em nove lactentes do Grupo I, oito do Grupo II e nove do Grupo III, sendo as médias obtidas para o Grupo I: $64,8 \mathrm{mcg} / \mathrm{mL}$, para o Grupo II: $58,9 \mathrm{mcg} / \mathrm{mL}$ e para o Grupo III: $63,1 \mathrm{mcg} / \mathrm{mL}$, sem diferença estatística significante (H calculado: 2,00 e H crítico: 5,99).

Em relação à hemoglobina, os níveis estiveram abaixo do valor referencial em 20 lactentes do Grupo I, 21 do Grupo II e 15 do Grupo III, sendo as médias obtidas para o Grupo I: 9, $41 \mathrm{~g} / \mathrm{dL}$, para o Grupo II: 9,29g/dL e para o Grupo III: $9,38 \mathrm{~g} / \mathrm{dL}$, não havendo diferença estatística significante (H calculado: 0,48 e H crítico: 5,99). O volume corpuscular médio (VCM) não mostrou alteraç̃̃es em nenhum dos grupos estudados (Grupo I $=82,4 \mu^{3}$, Grupo II $=81,8 \mu^{3}$ e Grupo III $=82,3 \mu^{3}$; H calculado: 3,58 e H crítico: 5,99). Quanto aos reticulócitos, as médias obtidas foram para o Grupo I: $70,310^{3} / \mathrm{mm}^{3}$, para o Grupo II: $75,010^{3} / \mathrm{mm}^{3}$ e para o Grupo III: 76,2 103/ $\mathrm{mm}^{3}$, não havendo diferença estatística significante (H calculado: 0,92 e H crítico: 5,99).

Ao correlacionar os valores de ácido fólico com os valores das demais variáveis por meio do coeficiente de correlação de Spearman, observou-se correlação positiva e significante entre os valores de ácido fólico e os de vitamina B12 para os três grupos estudados, com r calculado de 0,67 para o Grupo I, 0,59 para o Grupo II e 0,43 para o Grupo III, conforme observado na Tabela 2.

\section{Discussão}

A importância do estudo do comportamento do ácido fólico em lactentes aos quatro meses é decorrente da sua escassez na alimentação exclusivamente láctea e porque, nessa faixa etária, a reserva tecidual do folato é sabidamente baixa ${ }^{(22,25,29)}$.
Os lactentes do Grupo II alimentavam-se de LV pasteurizado e fervido, sendo este empregado nesse Grupo pelo seu menor custo. Para os lactentes do Grupo III, padronizou-se a fórmula láctea modificada para o primeiro semestre de vida, pelo conhecimento quantitativo de ácido fólico acrescido nesta fórmula.

As crianças atendidas no nosso ambulatório são, na maioria, de baixo nível socioeconômico. Esse aspecto foi observado em trabalhos anteriores, em âmbito populacional. Assim, Donangelo et al ${ }^{(23)}$ e Lehti ${ }^{(34)}$ demonstraram não haver diferença significante nos níveis de folato do leite de mães de baixo nível socioeconômico, quando comparadas com os de mães de melhor padrão socioeconômico. Verificase que os níveis de ácido fólico não se alteram em lactentes nos primeiros seis meses alimentados exclusivamente com LM, de acordo com o nível socioeconômico.

Em relação às 40 mães do Grupo I (LM), nenhuma fazia uso de suplementação vitamínica no momento do trabalho. Esse fato parece não ter importância, visto que Foged et a ${ }^{(24)} \mathrm{e}$ Smith et $a^{(26)}$ observaram que, ao administrar folato às mães, ocorre aumento de folato sangüíneo materno, sem elevação do nível de folato no leite. Tal suplementação somente teria valor na preservação do folato materno adequado caso a lactação se prolongar por um ano ou mais.

Em relação ao método de Dualcount por radioimunoensaio, os valores de referência foram obtidos em amostras populacionais e não em grupos exclusivos de lactentes e crianças. Os trabalhos relativos ao método ${ }^{(30,31)}$ também não são claros em relação às idades, porém sempre se reportam a voluntários, geralmente adultos. Raniolo et al ${ }^{(35)}$ concluíram que idade, gênero e volume celular total não interferem no valor de referência tanto para o ácido fólico, como para a vitamina B12. Salienta-se, entretanto, que a casuística em questão não abrange a faixa pediátrica, uma vez que consta de 99 indivíduos de 20 a 64 anos.

Os resultados referentes ao ácido fólico, em relação ao gênero, não mostraram diferenças significantes. Entretanto, ao comparar os três grupos independentemente do gênero, em análises de variância e teste de comparações múltiplas,

Tabela 2 - Coeficiente de correlação de Spearman ( $\mathrm{rs}$ ) entre o nível sérico de ácido fólico $(\mathrm{ng} / \mathrm{mL})$ e o de vitamina B12, ferro, hemoglobina, valor corpuscular médio e reticulócitos nos Grupos I (leite materno), II (leite de vaca) e III (fórmula)

\begin{tabular}{lccccc}
\hline $\begin{array}{l}\text { Grupos/ } \\
\text { exames }\end{array}$ & $\begin{array}{c}\text { Vitamina B12 } \\
(\mathbf{p g} / \mathbf{m L})\end{array}$ & $\begin{array}{c}\text { Ferro } \\
(\mathbf{m c g} / \mathbf{m L})\end{array}$ & $\begin{array}{c}\text { Hemoglobina } \\
(\mathbf{g} / \mathbf{d L})\end{array}$ & $\begin{array}{c}\text { VCM } \\
\left(\boldsymbol{\mu}^{3}\right)\end{array}$ & $\begin{array}{c}\text { Reticulócitos } \\
\left(\mathbf{1 0}^{3} / \mathbf{m m}^{3}\right)\end{array}$ \\
\hline G I & 0,67 & $-0,18$ & 0,22 & 0,10 & 0,25 \\
G II & 0,59 & 0,05 & $-0,08$ & 0,17 & 0,11 \\
G III & 0,43 & $-0,11$ & 0,03 & 0,05 & 0,30 \\
\hline
\end{tabular}


observou-se que os valores do Grupo II (LV) foram significantemente menores que os dos Grupos I (LM) e III (fórmula modificada), sendo que estes últimos não diferiram entre si. Tal resultado se deve provavelmente à baixa oferta de folato no LV pasteurizado e fervido.

Ao analisar a quantidade média de folatos, verifica-se que o LV contém $5,9 \mathrm{mcg} / 100 \mathrm{~mL}$; o LM $5,0 \mathrm{mcg} / 100 \mathrm{~mL}$ e as fórmulas modificadas $6,1 \mathrm{mcg} / 100 \mathrm{~mL}$. Apesar das cifras serem parecidas, a pasteurização e a fervura do LV, habitualmente utilizadas no nosso meio, acarretam perda de até $74 \%$ do ácido fólico, assim o LV torna-se fonte pobre dessa vitamina, caso seja o único alimento ofertado. Vale lembrar ainda a importância da melhor biodisponibilidade do ácido fólico encontrado no leite humano, apesar de seus níveis serem aparentemente baixos $^{(22,28,34)}$. Trabalhos isolados mostram a superioridade do $\mathrm{LM}$ em relação ao LV quanto à oferta de folatos ${ }^{(36,37)}$. Por outro lado, o LM apresenta níveis semelhantes de folato aos de LV modificado $^{(24-27)}$. Assim sendo, os resultados obtidos nos nossos lactentes estão de acordo com a literatura.

Ressalta-se que, além da escassez de trabalhos publicados, não foi encontrado nenhuma pesquisa que comparasse grupos homogêneos de lactentes no que diz respeito à faixa etária, bom estado nutricional, alimentação láctea exclusiva e sem intercorrências infecciosas, como no presente estudo. Os baixos níveis de ácido fólico encontrados neste trabalho, inclusive no grupo alimentado com leite materno, levam a crer que os valores de normalidade deveriam ser revistos na faixa pediátrica, sobretudo em lactentes. Provavelmente, os valores de referência devam ser mais baixos em Pediatria do que os encontrados na literatura adulta. $\mathrm{O}$ mesmo deve ocorrer com a vitamina B12.

Quanto aos resultados referentes à vitamina B12, não houve diferenças significantes entre os três grupos, embora os valores do Grupo II tenham sido menores em relação aos dos Grupos I e III. Tal resultado deve-se, provavelmente, ao fato de o LM e o LV modificado serem as melhores fontes dessa vitamina, sendo o último acrescido também de vitamina B12. Além disso, a dosagem sérica dessa vitamina também reflete menor aporte dietético, à semelhança do ácido fólico ${ }^{(26,31,37)}$. As diferenças não significativas entre os três grupos poderiam ser explicadas pela pouca deficiência no aporte alimentar e pelo armazenamento de B12, que pode suprir a necessidade até 12 meses $^{(20,21)}$.

Apesar da ferritina atualmente ser o melhor índice para avaliar a anemia ferropriva ${ }^{(6,29,38)}$, os valores de ferro obtidos abaixo do referencial foram nove casos no Grupo I (22,5\%), oito no II $(22,8 \%)$ e nove no III $(32,1 \%)$ e, embora sem diferença estatística entre os grupos, houve um predomínio de ferro sérico baixo no Grupo III, no qual a fonte alimentar é complementada com esse mineral ${ }^{(12)}$. Trabalhos ressaltam a deficiência desse elemento, em média aos quatro meses, independentemente do tipo de oferta láctea, salientando a necessidade de sua suplementação universal ${ }^{(7,18,38)}$.

Em relação aos valores de hemoglobina, observaram-se valores abaixo do valor referencial em 20 casos do Grupo I (50\%), 21 do Grupo II (60\%) e 15 do Grupo III (53,5\%). A prevalência de $50 \%$ de anemia no Grupo LM provavelmente não reflete a prevalência de anemia neste Grupo de lactentes, pois parece ser mais adequado, de acordo com Silva ${ }^{(39)}$, associar valores de ferritina para fazer este diagnóstico. Porém, se levarmos em consideração que baixas concentrações de hemoglobina estão associadas à anemia ferropriva ${ }^{(7,18,38,39)}$, é importante avaliar a necessidade de ferro nessa faixa etária.

Quanto ao VCM, não se observou nenhum caso de macrocitose nos três grupos estudados, fato confirmado por Herbert $^{(28)}$ e Zitoun ${ }^{(40)}$, que sugerem que o aumento ocorra em deficiências mais tardias de folatos. Matoth et al ${ }^{(36)} \mathrm{e}$ Pereira $e t a l^{(17)}$ consideram que, quando há carência de ferro associada, esta levaria à microcitose relativa, o que falsearia a macrocitose decorrente da falta de ácido fólico. Portanto, nosso trabalho concorda com esses autores que consideram o VCM um parâmetro pouco confiável na deficiência precoce de ácido fólico.

Pode-se concluir que os níveis de ácido fólico sérico, medidos por radioimunoensaio, foram adequados nos lactentes aos quatro meses dos Grupos I (LM) e III (fórmula), porém insatisfatórios para o Grupo II (LV). Diante dos resultados obtidos, seria aconselhável suplementar ácido fólico nos lactentes aos quatro meses alimentados exclusivamente com LV, não havendo essa necessidade nos alimentados exclusivamente com LM ou fórmulas modificadas. Finalmente, os resultados obtidos em lactentes, no presente estudo, poderiam ser utilizados como valores de referência nessa faixa etária.

\section{Agradecimentos}

Nossos agradecimentos ao Professor Doutor Neil Ferreira Novo pela ajuda valiosa no preparo da análise estatística e ao Professor Doutor Morton Aaron Scheinberg pelas minuciosas análises laboratoriais. 


\section{Referências bibliográficas}

1. Darby WJ. Some personal reflections on a half century of nutrition science: 1930s-1980s. Annu Rev Nutr 1985;5:1-24.

2. Burton BT. Nutrição humana: manual de nutrição na saúde e na doença. São Paulo: McGraw-Hill; 1979. p. 433-45.

3. Marcondes E, Machado DVM, Setian N, Carraza FR. Crescimento e desenvolvimento. In: Marcondes E, editor. Pediatria básica. $9^{a}$ ed. São Paulo: Sarvier; 2004. p. 35-63.

4. Bion FM, Teixeira SMFG. Estudo químico-fisiológico das vitaminas. In: Chaves $\mathrm{N}$, editor. Nutrição básica e aplicada. $2^{\mathrm{a}}$ ed. Rio de Janeiro: Guanabara-Koogan; 1985. p. 94-125

5. Sarni RS. Avaliação da condição nutricional. In: Lopez FA, Sigulem MD, Taddei JAAC, editores. Fundamentos da terapia nutricional em pediatria. São Paulo: Atheneu; 2002. p. 3-6.

6. Hillman RS. Agentes hematopoéticos: fatores de crescimento, sais minerais e vitaminas. In: Hardman JG, Limbird LE, editores. Goodman \& Gilman: as bases farmacológicas da terapêutica. $10^{\mathrm{a}}$ ed. Rio de Janeiro: McGraw Hill; 2003. p. 851-73.

7. Haiden N, Klebermass K, Cardona F, Schwindt J, Berger A, Kohlhauser-Vollmuth $\mathrm{C}$ et al. A randomized, controlled trial of effects of adding vitamin B12 and folate to erythropoietin for the treatment of anemia of prematurity. Pediatrics 2006; $118: 180-8$.

8. Drogueti DC, Camargo Penteado MV. Vitaminas. São Paulo: Manole; 2003.

9. Sociedade Brasileira de Pediatria. Departamento de Nutrologia. Manual de orientação para alimentação do lactente, do pré-escolar, do escolar, do adolescente e na escola. Rio de Janeiro, 2006.

10. Norton RC, Weffort VRS, Dantas Filho S, Fisberg M. Alimentação do lactente à adolescência. In: Ancona Lopez F, Campos Júnior D, editores. Tratado de pediatria. São Paulo: Manole; 2007. p. 1473-84.

11. Davidson GP, Townley RRW. Structural and functional abnormalities of the small intestine due to nutritional folic acid deficiency in infancy. J Pediatr 1977;90:590-4.

12. FAO/WHO Food Standards Programme. Codex Alimentarius. Codex standards for foods for special dietary use including foods for infants and children and related code of hygienic practice. Rome: FAO/WHO; 2000.

13. Fisberg M. Desmame adequado. In: Wehba J, editor. Nutrição da criança. São Paulo: BYK; 1991. p. 197-210.

14. Ancona Lopez F, Brasil ALD. Nutrição e dietética em clínica pediátrica. São Paulo: Atheneu; 2003.

15. Mayes PA. Estrutura e função das vitaminas hidrossolúveis. In: Murray RK, Granner DK, Mayes PA, Rodwell VW, editores. Harper: bioquímica. $9^{\mathrm{a}}$ ed. São Paulo: Atheneu; 1999. p. 582-96

16. Bernstein LH, Gutstein S, Weiner S, Efron G. The absorption and malabsorption of folic acid and its polyglutamates. Am J Med 1970;48:570-9.

17. Pereira Júnior JC. Leite de vaca fervido e desnutrição infantil. Rev Paul Pediatr 1987;5:43-4.

18. Pereira Júnior JC. Carência de ácido fólico: uma revisão crítica. Rev Paul Pediatr 1990;8:4-8.

19. Kones R. Folic acid, 1991: an update, with new recommended daily allowances. South Med J 1990;83:1454-8.

20. Liberato SC, Pinheiro-Sant'Ana HM. Fortification of industrialized foods with vitamins. Rev Nutr (Campinas) 2006;19:215-31.
21. Mackey AD, Picciano MF. Maternal folate status during extended lactation and the effect of supplemental folic acid. Am J Clin Nutr 1999;69:285-92.

22. Olivares Martínez AB, Ros Berruezo G, Bernal Cava MJ, Martinez Gracia C Periago Castón MJ. Folate and folic acid intake estimation and food enrichment requirements. Arch Latinoam Nutr 2005;55:5-14.

23. Donangelo CM, Trugo NMF, Koury JC, Barreto Silva MI, Freitas LA, Feldheim W et al. Iron, zinc, folate and vitamin B12 nutritional status and milk composition of low-income Brazilian mothers. Eur J Clin Nutr 1989;43:253-66.

24. Foged N, Lillquist K, Rolschau J, Blaabjerg O. Effect of folic acid supplementation on small-for-gestational-age infants born at term. Eur J Pediatr 1989;149:65-7.

25. Olivares M, Anderson M, Llaguno S, Stekel A.. Folato sérico y eritrocitario en el lactante. Rev Chil Pediatr 1983;54:246-8.

26. Smith AM, Picciano MF, Deering RH. Folate supplementation during lactation: maternal folate status, human milk folate content, and their relationship to infant folate. J Pediatr Gastroenterol Nutr 1983;2:622-8.

27. Salmenpera L, Perheentupa J, Siimes MA. Folate nutrition is optimal in exclusively breast-fed infants but inadequate in some of their mothers and in formula-fed infants. J Pediatr Gastroenterol Nutr 1986;5:283-9.

28. Herbert V. Studies of folate deficiency in man. Proc R Soc Med 1964; $57: 377-84$

29. Olivares M, Anderson M, Llaguno S, Chadud P, Stekel A. Folato sérico y eritrocitario en el lactante: Influencia de la nutrición de hierro. Rev Chil Pediatr 1986;57:342-4.

30. Melse-Boonstra A, Verhoef P, West C. Quantifying folate bioavailability: a critical appraisal of methods. Curr Opin Clin Nutr Metab Care 2004;7:539-45.

31. Chen IW, Silberstein EB, Maxon HR, Volle CP, Sohnlein BH. Semiautomated system for simultaneous assays of serum vitamin B12 and folic acid in serum evaluated. Clin Chem 1982;28:2161-5.

32. Hollander M, Wolfe DA. Nonparametric statistical methods. New York: Wiley; 1973.

33. Siegel S. Estatística no paramétrica. México: Trillas; 1975.

34. Lehti KK. Breast milk folic acid and zinc concentrations of lactating, low socioeconomic, Amazonian women and the effect of age and parity on the same two nutrients. Eur J Clin Nutr 1990;44:675-80.

35. Raniolo E, Phillipou G, Paltridge G, Sage RE. Evaluation of a comercial radioassay for the simultaneous estimation of vitamin B12 and folate, with subsequent derivation of the normal reference rage. J Clin Pathol 1984;37:1327-35.

36. Matoth Y, Pinkas A, Zamir R, Mooallem F, Grossowicz N. Studies on folic acid in infancy. Pediatrics 1964;33:507-11.

37. Matoth Y, Pinkas A, Sroka CH. Studies on folic acid in infancy: III-Folates in breast-fed infants and their mothers. Am J Clin Nutr 1965;16:356-9.

38. Rao S, Yajnik CS, Kanade A, Fall CH, Margetts BM, Jackson AA et al. Intake of micronutrient-rich foods in rural Indian mothers is associated with the size of their babies at birth: Pune Maternal Nutrition Study. J Nutr 2001;131:1217-24

39. Silva AP. Avaliação da intervenção na deficiência de ferro com fortificação de ferro aminoquelato. Estudo em crianças de creches do município de Lins-SP [tese de doutorado]. Botucatu (SP): Unesp; 2006.

40. Zittoun J. Les anémies macrocytaires. Rev Prat 1989;39:2133-7. 